\title{
Novel intron 2 polymorphism in the melanophilin gene is in Hardy-Weinberg equilibrium and is not associated with coat color in goats
}

\author{
Mufliat A. Adefenwa ${ }^{1,2}$, Brilliant O. Agaviezor ${ }^{1,3}$, Sunday O. Peters ${ }^{1,4}$, Matthew Wheto ${ }^{5}$, \\ Marcos De Donato ${ }^{1}$, Bolaji N. Thomas ${ }^{7}$, Ikhide G. Imumorin ${ }^{1 *}$ \\ ${ }^{1}$ Department of Animal Science, Cornell University, Ithaca, USA \\ ${ }^{2}$ Department of Cell Biology and Genetics, University of Lagos, Lagos, Nigeria \\ ${ }^{3}$ Department of Animal Science and Fisheries, University of Port Harcourt, Port Harcourt, Nigeria \\ ${ }^{4}$ Department of Animal Science, Berry College, Mount Berry, USA \\ ${ }^{5}$ Department of Animal Breeding and Genetics, University of Agriculture, Abeokuta, Nigeria \\ ${ }^{6}$ Department of Livestock Production, Niger Delta University, Amassomma, Nigeria \\ ${ }^{7}$ Department of Biomedical Sciences, Rochester Institute of Technology, Rochester, USA \\ Email: *igi2@cornell.edu
} Oludotun J. Ekundayo ${ }^{5}$, Moses Okpeku' ${ }^{6}$, Bola O. Oboh' ${ }^{2}$, Khalid O. Adekoya ${ }^{2}$, Christian O. N. Ikeobi ${ }^{5}$,

Received 25 January 2013; revised 28 February 2013; accepted 15 March 2013

Copyright (C) 2013 Mufliat A. Adefenwa et al. This is an open access article distributed under the Creative Commons Attribution License, which permits unrestricted use, distribution, and reproduction in any medium, provided the original work is properly cited.

\begin{abstract}
Pigmentation plays important adaptation and physiological efficiency roles in animals. In the sequence of a 648 bp fragment representing intron 1, exon 2, and part of intron 2 of the MLPH mammalian pigmentation gene, we identified a novel g.469C $>$ G mutation in intron 2, and genotyped it in 266 Nigerian goats using PCR-RFLP analysis. The $C$ allele had frequencies of $0.9625,0.9804$ and 0.97405 in West African Dwarf (WAD), Sahel (SH) and Red Sokoto (RS) breeds, respectively. The $G$ allele was the highest in WAD (0.0375), followed by RS (0.02595), and then SH (0.0196). Overall low FIS and FST and high Nm values demonstrate little differentiation within and among the goat breeds at this intronic locus. This g.469C > G polymorphism in MLPH gene is the first in any goat breed and also first in Nigerian goats. Our results suggest that this intronic SNP locus is maintained at Hardy-Weinberg equilibrium $(P<0.05)$ and the lack of association of this SNP with coat color may indicate its neutrality in goats.
\end{abstract}

Keywords: Coat Color; Goats; Melanophilin; Nigeria; Intron 2; SNP; PCR-RFLP

\section{INTRODUCTION}

Several coat colors and color patterns are common

${ }^{*}$ Corresponding author. among mammals and have evolved through natural and sexual selection [1]. In many mammals, pigmentation primarily plays a role in protection against ultraviolet radiation but may also help in immune system function [1]. The pigment granules, eumelanin and pheomelanin, are produced in melanosomes, membrane bound organelles present in melanocytes which are found in the basal skin layer [2]. Melanosomes gradually develop melanin as they mature and are translocated from the perinuclear region to the periphery (dendrites) of the melanocytes where they are then transferred to neighboring keratinocytes in the middle and upper layers of the skin. Skin and hair colour of many mammals are determined by the form, contents, transfer and accumulation of melanosomes in keratinocytes. More deeply-pigmented skins usually contain a larger and higher number of melanosomes when compared to light-pigmented skins [3].

Mammalian pigmentation is controlled by several genes, the products of which form the melanosomal particles or are involved in their maturation and dispersion. Many researchers have reported the movement of melanosomes in melanocytes, with defects leading to the three types of Griscelli syndrome in humans, the ashen, leaden and dilute phenotype in mice, and the dilute coat colour phenotype in several animals. They further reported that they are controlled by three major proteins, which include: myosin VA (MYO5A), Rab27A and melanophilin $(M L P H)$ [1,4,5]. This interaction between melanophilin and myosin $\mathrm{Va}$ is strengthened by the presence of a melanocyte-specific exon $\mathrm{F}$ in the tail 
domain of myosin-Va [4,6,7].

Mutations in melanophilin gene have been associated with coat color dilution in some mammals. Philipp et al. [8] reported strong associations of single nucleotide polymorphisms in exon 2 of $M L P H$ and color in dilute Doberman pinschers, Beagles, and Large munsterlanders and in exon 7 in dilute German pinschers. Zhou et al. [9] also found a missense mutation of g.115844A $>\mathrm{G}$ in exon 10 in goat melanophilin gene and inferred from their results that allele $\mathrm{G}$ might be responsible for the tan color observed in some of the goat breeds in China. There are no published studies on melanophilin gene in Nigerian indigenous goats. The three major goat breeds in Nigeria exhibit specific coat colors except for occasional within breed color variation. The West African Dwarf is usually black; the Sahel goat is commonly white while the Red Sokoto is mostly red. In this study, we identified a novel intronic SNP in the caprine melanophilin gene and investigated the association of this polymorphism with coat color and its differentiation among Nigerian goat populations.

\section{MATERIALS AND METHODS}

\subsection{Animals and DNA Samples}

Nigeria is located in West Africa on the Gulf of Guinea (latitude $10^{\circ} 00^{\prime} \mathrm{N}$, longitude $8^{\circ} 00^{\prime} \mathrm{E}$ ) with a total area of $923,768 \mathrm{~km}^{2}$. Nigeria is bounded by Niger, Benin and Cameroon Republics on the North, West and East, re- spectively. The sample was made up of 266 goats of the three major breeds of goats in Nigeria; WAD $(n=80)$, RS $(n=135)$ and SH $(n=51)$ collected from farms and markets across Nigeria, according to the geographical distribution of the breeds published by Blench [10] with locations shown in Figure 1. Blood samples were collected by jugular venipuncture from individual animals and genomic DNA from collected blood samples were isolated using ZymoBead ${ }^{\mathrm{TM}}$ Genomic DNA kit (Zymo Research Corporation, Irvine, CA, USA) following the manufacturer's instructions. Quantification of DNA yield and assessment of quality were done using a Nanodrop ND-100 UV/Vis Spectrophotometer (Nanodrop Technologies, Inc., Wilmington, DE, USA).

\subsection{Isolation and Sequencing of Melanophilin Gene Fragments}

Using information from Feng et al. [11], a pair of PCR primers (F: 5'-CGTGGGTTCCCTTATTTTGAC-3' and R: 5'-ATCCTGGCTTCTGGGTGTTG-3') was synthesized to amplify a $648 \mathrm{bp}$ fragment spanning intron 1 , exon 2 and part of intron 2. PCR amplifications were carried out in a $\mathrm{C} 1000^{\mathrm{TM}}$ Thermal Cycler (Biorad, Hercules, CA, USA) in a total reaction volume of $20 \mu \mathrm{L}$ containing approximately $50 \mathrm{ng}$ DNA, 10 pmol of each primer in AccuPower ${ }^{\mathrm{TM}}$ PCR Premix (Bioneer Corporation, Alameda, CA, USA). The PCR cycling conditions are as follows: denaturation at $95^{\circ} \mathrm{C}$ for $4 \mathrm{~min}$, followed by 35 amplification cycles of denaturation at $94^{\circ} \mathrm{C}$ for 30

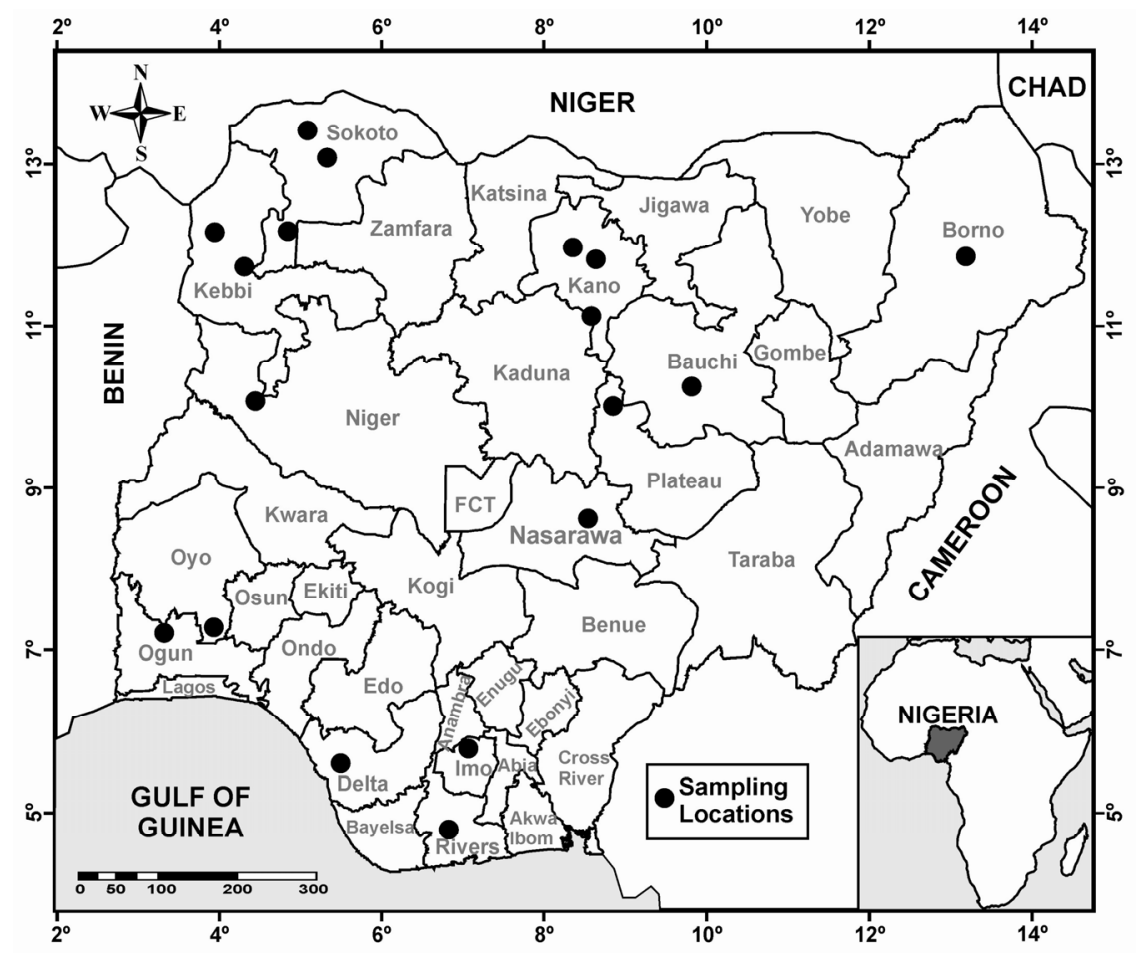

Figure 1. Sites of sampling collection. 
s, annealing at $56^{\circ} \mathrm{C}$ for $30 \mathrm{~S}$, extension at $72^{\circ} \mathrm{C}$ for $3 \mathrm{~min}$, followed by an extended elongation at $72^{\circ} \mathrm{C}$ for $10 \mathrm{~min}$. PCR products were detected on $1.5 \%$ agarose gel including ethidium bromide, and photographed under UV light. Sequencing of the amplified fragments was carried out using the same PCR primers with the Applied Biosystems Automated 3730 DNA Analyzer (Applied Biosytems, Carlsbad, CA, USA) using Big Dye Terminator chemistry and AmpliTaq-FS DNA Polymerase.

\subsection{Genotyping of Goat MLPH Gene by PCR-RFLP}

In order to identify SNPs of $M L P H$ gene in Nigerian goats, sequences derived from 20 animals were aligned using ClustalW program

(http://www.ebi.ac.uk/Tools/clustalw/). The transversion 469C > G, according to EU316218, was detected. This SNP was analyzed by PCR-RFLP in a total of 266 goats. HinP11 restriction enzyme (Fermentas Life Sciences, Glen Burnie, MD, USA), recognizing the palindromic tetranucleotide sequence $\mathrm{G} \downarrow \mathrm{CGC}$ was used for restriction enzyme digestion according to NEBcutter V2.0. Aliquots of $15 \mu \mathrm{L}$ PCR products, including $2 \mu \mathrm{L} 10 \mathrm{X}$ buffer with BSA, were digested with $1 \mu \mathrm{L}(10 \mathrm{U}) \mathrm{HinP} 11$ for $16 \mathrm{~h}$ at $37^{\circ} \mathrm{C}$. Thermal inactivation of the restriction enzyme was thereafter done by incubation at $65^{\circ} \mathrm{C}$ for $20 \mathrm{~min}$. The digested products were detected by electrophoresis on $2.0 \%$ agarose gel including $0.5 \mu \mathrm{g} / \mathrm{mL}$ of ethidium bromide.

\subsection{Statistical Analysis}

Genotypic frequencies, allelic frequencies and Hardy-Weinberg equilibrium (HWE) test were performed using POPGENE32 software (version 1.32). Genetic diversity of each breed, population and genetic differentiation among different breeds and populations including Wright's fixation indices, and Shannon Indices were obtained using the same software. Comparisons of allelic frequencies among breeds were done using chi-square analysis. All tests were assessed at a significance level of $5 \%$.

\subsection{In-Silico Analyses}

In-silico functional analyses were obtained using Splice Site Prediction by Neural Network and Splicing Regulation Online Graphical Engine (Sroogle).

\section{RESULTS}

\subsection{Goat MLPH Gene Sequences and SNP Identification}

The PCR primers produced a 648 bp fragment (Figure 2), spanning intron 1, exon 2 and part of intron 2 (GenBank
EU316218). The transversion g.469C $>\mathrm{G}$ was identified in intron 2 from aligning sequences obtained from 20 animals. This mutation was analyzed in a larger number of animals of the three Nigerian goat breeds using PCR-RFLP method. Digestion of the PCR products with HinP11 yielded two fragments (532 and $116 \mathrm{bp}$ ) for $\mathrm{C}$ allele and one fragment (648 bp) for $G$ allele. Genotype $\mathrm{CC}, \mathrm{CG}$ and GG, therefore, demonstrated two, three and one band respectively (Figure 3 ).

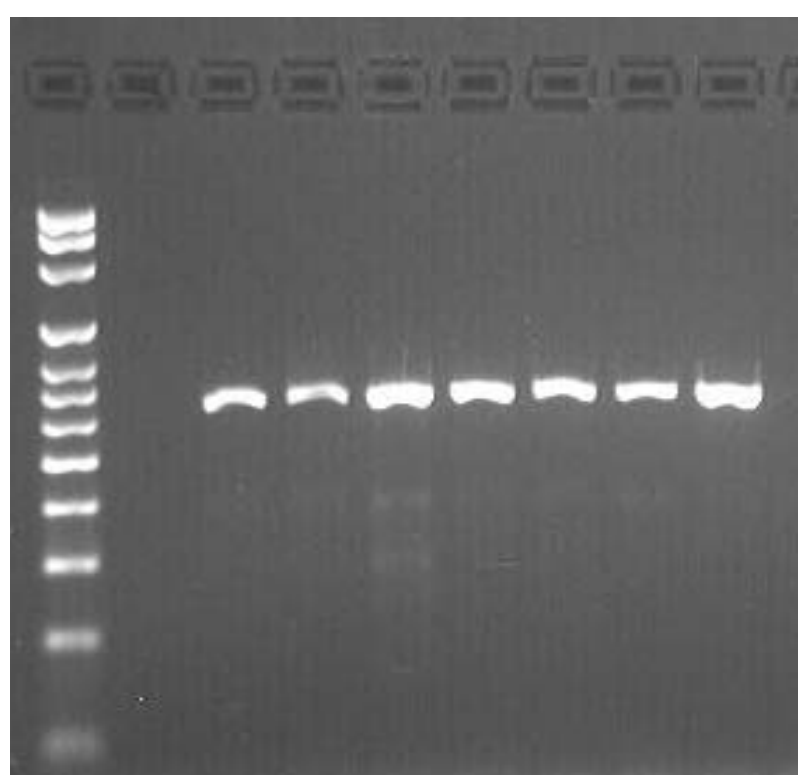

Figure 2. Amplified fragments of the Melanophilin gene. The first lane from the left contains the DNA marker. $\mathrm{W}=$ Well (points that PCR products were loaded) casted on gel. B= Bands of amplified DNA fragments.

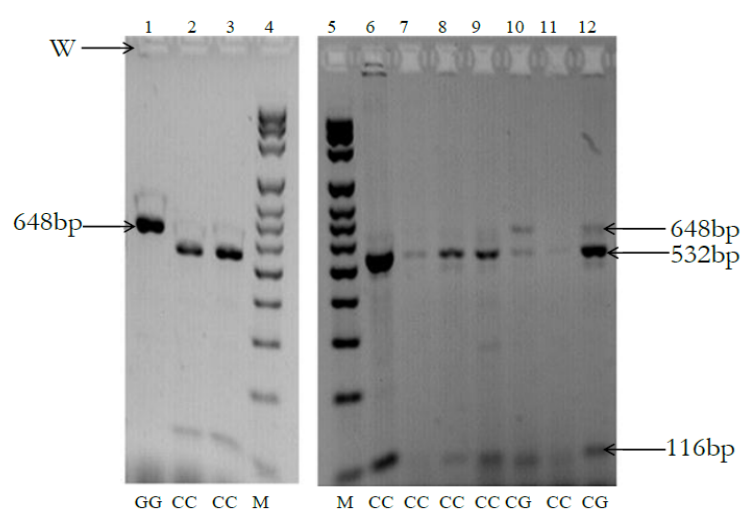

Figure 3. Result of PCR-RFLP by Hinp1I. Digestion of the PCR products with HinplI yielded two fragments (532 and 116 bp) for $\mathrm{C}$ allele and one fragment (648 bp) for $\mathrm{G}$ allele. Genotypes CC, CG and GG, therefore, demonstrated two, three and one band respectively $\mathrm{M}$ refers to DNA Marker. Lane 1 illustrates genotype GG with one band of $648 \mathrm{bp}$, lanes $2,3,6,7,8$, 9 and 11 illustrate genotype $\mathrm{CC}$ with two bands of $116 \mathrm{bp}$ and $532 \mathrm{bp}$, and lanes 10 and 12 illustrate genotype CG three bands of $116 \mathrm{bp}, 532 \mathrm{bp}$ and $648 \mathrm{bp}$. Lanes 4 and 5 contain DNA marker. 


\subsection{The Distribution of g.469C $>\mathrm{G}$ in Nigerian Goat Breeds}

Genotypic frequencies, allelic frequencies and the probability of departure from HWE of the different goat breeds are shown in Table 1. Allele $\mathrm{C}$ had frequencies of $0.9741,0.9804$ and 0.9625 in RS, SH and WAD goats, respectively. WAD had the highest frequency $(0.0375)$ of allele G, followed by RS (0.0259) and then SH (0.0196). Also, homozygous GG was found only in the RS breed. The chi-square test based on the allelic frequencies revealed no significant differences between the breeds for g.469C $>$ G (Table 2). Both WAD and SH breeds appear to be in HWE for g.469C $>\mathrm{G}(\mathrm{P}<0.05)$. The deficit of homozygote GG individuals in SH and WAD probably accounts for the deviation from HWE in the RS breed. Overall, our results suggest that the Nigerian goat population is in HWE with respect to this locus $(\mathrm{P}<0.05)$.

\subsection{Genetic Diversity and Differentiation of g.469C > G in Different Nigerian Goat Breeds}

Tables 3 and $\mathbf{4}$ show the genetic diversity and differentiation of g. $469 \mathrm{C}>\mathrm{G}$ in Nigerian goat breeds. The observed heterozygosity ranged from 0.0370 (RS) to 0.0750 WAD. The Levene and Nei's expected heterozygosity ranged from 0.0388 (SH) to 0.0726 (WAD) and $0.0384(\mathrm{SH})$ to 0.0722 (WAD), respectively. The two kinds of expected heterozygosity had similar values, with little difference in observed heterozygosity. There was however, a somewhat large difference in the observed heterozygosity from the two kinds of expected heterozygosity in RS. Only RS goats (red coat color) showed a positive value of Wright's fixation index also indicating an excess of homozygotes in this breed. The relative magnitude of genetic variation of g.469C $>\mathrm{G}$ for each breed is WAD $>\mathrm{RS}>\mathrm{SH}$ based on the Shannon Index value. All three goat breeds exhibited low genetic diversity at g.469C $>$ G. Table 4 shows overall low FIS and FST values and high $\mathrm{Nm}$ value.

\subsection{Functional In-Silico Analysis}

Functional in-silico analysis of the sequenced portion of the gene using Splice Site Prediction by Neural Network shows that one of the Splice donor site starts at site 103 and ends at 117 and the other starts at 237 and ends at 251 with scores 0.96 and 0.99 , respectively. The acceptor sites were found to start at 89 and 363 and ended at 129 and 403 respectively with 0.93 and 0.69 scores, respectively. The point mutation g.469C $>\mathrm{G}$ was found in a regulator with 0.0354 score according to the Voelker down dataset as implemented in Sroogle.

\section{DISCUSSION}

We have analyzed this novel g.469G $>\mathrm{C}$ intronic mutation for possible association with coat color because it has been found that mutations in intronic regions can alter gene expression by affecting regulation, impairing protein synthesis and causing aberrant splicing [12-14]. In-silico functional analysis of this mutation shows that this mutation is in a splicing regulatory sequence and can therefore potentially affect splicing of the caprine melanophilin mRNA.

The positive value of Wright's fixation index observed in RS breed is probably due to its distribution. This breed is the most common and most widespread breed of goat in Nigeria. Its use for high quality leather has had important positive consequences on the distribution and propagation of this breed [10]. The relatively low degree of genetic variation for the SH breed can be attributed to its restricted geographical distribution. This breed is

Table 1. Genotype and gene frequencies of g.469C $>\mathrm{G}$ in Nigerian goat Breeds.

\begin{tabular}{|c|c|c|c|c|c|c|c|}
\hline \multirow{2}{*}{ Goat Breed } & \multirow{2}{*}{ Sample Size } & \multicolumn{3}{|c|}{ Genotypic Frequencies } & \multicolumn{2}{|c|}{ Allelic Frequencies } & \multirow{2}{*}{$\mathrm{HW}^{\mathrm{c}}$} \\
\hline & & $\mathrm{CC}$ & $\mathrm{CG}$ & GG & $\mathrm{C}$ & G & \\
\hline Red Sokoto & 135 & 0.956 & 0.037 & 0.007 & 0.974 & 0.026 & 0.001 \\
\hline Sahel & 51 & 0.961 & 0.039 & 0.000 & 0.980 & 0.020 & 0.920 \\
\hline West African Dwarf & 80 & 0.925 & 0.075 & 0.000 & 0.963 & 0.038 & 0.751 \\
\hline
\end{tabular}

${ }^{\mathrm{c}}$ Probability of departure from Hardy-Weinberg equilibrium.

Table 2. $\chi^{2}$ and $\mathrm{P}$ values for differences among the three Nigerian goat breeds based on allelic frequencies.

\begin{tabular}{cccc}
\hline & Red Sokoto & Sahel & West African Dwarf \\
\hline Red Sokoto & - & $0.125(\mathrm{P}=0.724)$ & $0.459(\mathrm{P}=0.498)$ \\
Sahel & & - & $0.674(\mathrm{P}=0.412)$ \\
West African Dwarf & & & - \\
\hline
\end{tabular}


Table 3. The heterozygosis of g. $469 C>G$ in different Nigerian goat breeds.

\begin{tabular}{|c|c|c|c|c|c|c|c|c|c|}
\hline \multirow{2}{*}{ Breed $^{*}$} & \multirow{2}{*}{ Sample Size } & \multicolumn{2}{|c|}{ Observed Value } & \multicolumn{2}{|c|}{ Expected $^{* *}$ Values } & \multirow{2}{*}{ Nei's $\mathrm{H}^{* * *}$} & \multirow{2}{*}{$\mathrm{Ne}$} & \multirow{2}{*}{ Fis } & \multirow{2}{*}{ I } \\
\hline & & Hom & Het & Hom & Het & & & & \\
\hline RS & 135 & 0.963 & 0.037 & 0.949 & 0.051 & 0.051 & 1.053 & 0.267 & 0.120 \\
\hline SH & 51 & 0.961 & 0.039 & 0.961 & 0.039 & 0.038 & 1.040 & -0.020 & 0.097 \\
\hline WAD & 80 & 0.925 & 0.075 & 0.927 & 0.073 & 0.072 & 1.078 & -0.039 & 0.160 \\
\hline Overall & 266 & 0.951 & 0.049 & 0.945 & 0.055 & 0.055 & 1.058 & 0.108 & 0.128 \\
\hline
\end{tabular}

*Breed: RS = Red Sokoto; SH = Sahel; WAD = West African Dwarf. ${ }^{* *}$ Expected homozygosity and heterozygosity were computed using Levene (1949); ${ }^{* * *}$ Nei's 1973 expected heterozygosity; Ne = effective number of alleles [Kimura and Crow (1964)]; I = Shannon's information index [(Lewontin (1972)]; Fis = Wright's fixation index.

Table 4. Summary of F-Statistics and Gene Flow [Nei (1987)] of g. $469 C>G$ between Nigerian goat breeds.

\begin{tabular}{cccc}
\hline Fis & Fit & Fst & $\mathrm{Nm}$ \\
\hline 0.061 & 0.063 & 0.002 & 122.323 \\
\hline
\end{tabular}

found mostly along the northern border of Nigeria, particularly in Borno State [10].

Heterozygosity denotes the frequency of heterozygosis at the tested site (g.469C > G) in the populations and represents an appropriate index for population genetic variation. In this study, the values of expected heterozygosity were all less than 0.5 within the 3 goat breeds. This shows that genetic diversity was deficient at this site. The effective number of alleles and Shannon's Information Indices showed similar trends as expected heterozygosity in the 3 goat breeds. This relatively low genetic diversity at the g.469C $>$ G locus may be due to the directional selection for coat color. The Veterinary Service in Sokoto Province once castrated 219,688 non-red male goats in 5 years to replace the non-red skins with the more valuable red in the local markets [10]. The overall low FIS and FST values and high Nm value observed in this study showed that there is little or no differentiation within and among the breeds based on g. $469 \mathrm{C}>\mathrm{G}$. The lower genetic diversity of this mutation site contrasts with the higher genome diversity based on microsatellite DNA of goat breeds in Nigeria $[15,16]$.

From this study, the g.469C $>$ G mutation does not seem to be associated with coat color based on the allele and genotypic frequencies in the different breeds. This contrasts with the findings of Zhou et al. [9] who found an association between coat color and the missense mutation g. $11584 \mathrm{~A}>\mathrm{G}$ in exon 10 of caprine MLPH gene. The $\mathrm{G}$ allele was mostly found in Chengdu Ma and Nanjiang Brown goat (including three strains), in which homozygote GG was only found. They inferred that allele $\mathrm{G}$ might be a candidate site for the dilute coat color (tan) found in Nanjiang Brown goat and Chengdu Ma goat. $\mathrm{Li}$ et al. [17] also found an association between nine completely linked SNPs and dilute coat color (tan) of Chengdu Ma goat.
A single base pair deletion in exon 2 of $M L P H$ transcripts that introduces a stop codon 11 amino acids downstream, resulting in the truncation of the bulk of the $M L P H$ protein, was also identified by Ishida et al. [18]. They found this homozygous variant in 97 unrelated dilute cats representing 26 cat breeds and random-bred cats, along with 89 unrelated wild-type cats representing 29 breeds and random bred cats. They identified a single haplotype in dilute cats, suggesting that a single mutation event in $M L P H$ gave rise to dilute in domestic cats. In chickens also, Vaez et al. [19] identified a strong association between a mutation in exon 1 of the $M L P H$ gene and the diluted pigmentation phenotype in Lavender chickens. The g.469C > G mutation was, however, not reported in the earlier mentioned studies.

In summary, this novel SNP is maintained in HWE and is not associated with coat color in Nigerian goats. Further studies to test for additional variants in $M L P H$ gene are needed to understand if other molecular differences in $M L P H$ affect coat color in these and other populations.

\section{ACKNOWLEDGEMENTS}

Financial support from College of Agriculture and Life Sciences, Cornell University, Ithaca, NY is gratefully acknowledged.

\section{REFERENCES}

[1] Aspengren, S., Hedberg, D., Sköld, H.N. and Wallin, M. (2009) New insights into melanosome transport in vertebrate pigment cells. International Review of Cell \& Molecular Biology, 272, 245-302. doi:10.1016/S1937-6448(08)01606-7

[2] Hearing, V.J. and Tsukamoto, K. (1991) Enzymatic control of pigmentation in mammals. FASEB Journal, 5, 2902-2909.

[3] Sturm, R.A. (2006) A golden age of human pigmentation genetics. Trends in Genetics, 22, 464-468. doi:10.1016/j.tig.2006.06.010

[4] Fukuda, M., Kuroda, T.S. and Mikoshiba, K. (2002) Slac2-a/melanophilin, the missing link between Rab27 and myosin Va. The Journal of Biological Chemistry, 277, 
12432-12436. doi:10.1074/jbc.C200005200

[5] Drögemüller, C., Philipp, U., Haase, B., Günzel-Apel, A. and Leeb, T. (2007) A noncoding melanophilin gene (MLPH) SNP at the splice donor of exon 1 represents a candidate causal mutation for coat colour dilution in dogs. Journal of Heredity, 98, 468-473. doi:10.1093/jhered/esm021

[6] Goud B (2002) How Rab proteins link motors to membranes. Nature Cell Biology, 4, E77-E78. doi:10.1038/ncb0402-e77

[7] Hume, A.N., Tarafder, A.K., Ramalho, J.S., Sviderskaya, E.V. and Seabra, M.C. (2006) A coiled-coil domain of melanophilin is essential for myosin Va recruitment and melanosome transport in melanocytes. Molecular Biology of the Cell, 17, 4720-4735. doi:10.1091/mbc.E06-05-0457

[8] Philipp, U., Hamann, H., Mecklenburg, L., Nishino, S., Mignot, E., Günzel-Apel, A.R., Schmutz, S.M. and Leeb, T. (2005) Polymorphisms within the canine MLPH gene are associated with dilute coat colour in dogs. $\mathrm{BMC} \mathrm{Ge}$ netics, $\mathbf{6}, 34$.

[9] Zhou, R.Y., Feng, F.J., Li, X.L., Li, L.H., Tang, C.J., Wang, J.T. and Zheng, H.Q. (2010) Study on transition of g.11584A $>\mathrm{G}$ of goat melanophilin gene in different populations. African Journal of Biotechnology, 9, 23282332.

[10] Blench, R. (1999) Traditional livestock breeds: Geographical distribution and dynamics in relation to the ecology of West Africa. Working Paper 122, Overseas Development Institute, Portland House, Stag Place, London, 69p.

[11] Feng, F.J., Li, X.L., Zhou, R.Y., Zheng, G.R., Li, L.H. and Li, D.F. (2009) Characterization and SNP identification part of the goat melanophilin gene. Biochemical Genetics, 47, 198-206. doi:10.1007/s10528-008-9217-z

[12] Miné, M., Brivet, M., Touati Grabowski, P., Abitbol, M. and Marsac, C. (2003) Splicing error in E1 $\alpha$ pyruvate dehydrogenase mRNA caused by novel intronic mutation responsible for lactic acidosis and mental retardation. The Journal of Biological Chemistry, 278, 11768-11772. doi:10.1074/jbc.M211106200

[13] Holla, Ø.L., Nakken, S., Mattingsdal, M., Ranheim, T., Berge, K.E., Defesche, J.C. and Leren, T.P. (2009) Effects of intronic mutations in the LDLR gene on premRNA splicing: Comparison of wet-lab and bioinformatics analyses. Molecular Genetics and Metabolism, 96, 245-252. doi:10.1016/i.ymgme.2008.12.014

[14] Nascimbeni AC, Fanin M, Tasca E and Angelini A (2010) Transcriptional and translational effects of intronic CAPN3 gene mutations. Human Mutation, 31, E1658E1669. doi:10.1002/humu.21320

[15] Okpeku, M., Peters, S.O., Ozoje, M.O., Adebambo, O.A., Agaviezor, B.O., O’Neill, M.J. and Imumorin, I.G. (2011) Preliminary analysis of microsatellite-based genetic diversity of goats in southern Nigeria. Animal Genetic Resources, 49, 33-41 doi:10.1017/S207863361100035X

[16] Adebambo, A.O., Adebambo, O., Williams, J.L., Blott, S. and Urquart, B. (2011) Genetic distance between two popular Nigerian goat breeds used for milk production. http://www.lrrd.org/lrrd23/2/adeb23026.htm

[17] Li, X.L., Feng, F.J., Zhou, R.Y., Li, L.H., Zheng, H.Q. and Zheng, G.R. (2010) Nine linked SNPs found in goat melanophilin (mlph) gene. Journal of Bioinformatics and Sequence Analysis, 2, 85-90.

[18] Ishida, Y., David, V.A., Eizirik, E., Schäffer, A.A., Neelam, B.A., Roelke, M.E., Steven, S.H., O’Brien, S.J. and Menotti-Raymond, M. (2006) A homozygous single-base deletion in MLPH causes the dilute coat color phenotype in the domestic cat. Genomics, 88, 698-705. doi:10.1016/j.ygeno.2006.06.006

[19] Vaez, M., Follett, S.A., Bed'hom, B., Gourichon, D., Tixier-Boichard, M. and Burke, T. (2008) A single pointmutation within the melanophilin gene causes the lavender plumage colour dilution phenotype in the chicken. BMC Genetics, 9, 7. doi:10.1186/1471-2156-9-7 